\title{
Belmiro de Almeida \\ e o realismo: da glosa ao encanto da proximidade
}

\author{
Antonio Carlos Santos*
}

\begin{abstract}
Resumo:
Através de uma versão de Belmiro de Almeida de um quadro de Henri Gervex, pensar a questão do realismo visto não como mímesis, mas como momento de ruptura com o regime representativo (Rancière), e da "cópia" como glosa, ou seja, como versão canibal de um "original" europeu.
\end{abstract}

\section{Palavras-chave:}

Mímesis; realismo; século XIX

Em um ensaio em que faz um panorama das artes plásticas do século XIX, Alexandre Eulálio (1992) faz menção, en passant, a Belmiro de Almeida censurando no pintor que havia se formado na Academia Imperial de Belas-Artes uma relação interesseira com o "público que compra". Assinala no artista uma posição dúplice: por um lado, "experimenta técnicas divisionistas desde 1890", por outro, "leva avante, para uso do público que compra, glosas diversas da obra de um Gervex" (EULÁLIO, 1992, p.160). De fato, não apenas a Dame à la rose, de 1905, mas mesmo Arrufos, o quadro que havia pintado em 1887 e vendido à Academia para angariar fundos para uma nova viagem a Paris, eram versões, ou glosas como dizia Eulálio, de telas do artista francês. O quadro de Henri Gervex, intitulado Le retour du bal, chamou a atenção de Émile Zola que incluía o pintor entre os naturalistas. O escritor, que fez de Gervex modelo para o personagem Fagerolles, de L'Oeuvre, descreve assim a cena pintada na tela: "uma cena da vida mundana, com uma mulher soluçando em um canapé, enquanto o marido ou amante, de pé (sic) retirava nervosamente suas luvas; e havia nesse pequeno drama íntimo uma verdade de atitudes, um amor por nossa vida contemporânea que faziam desse quadro uma tentativa das mais interessantes". (Zola 1989, p. 293). Huysmans, um ano antes, descrevia a cena com mais detalhes, não sem antes dizer que não gostava muito do quadro:

A cena está assim colocada: um senhor vestido de negro está sentado e inclinado para a frente. Ele acaba de receber da mulher que chora com o rosto escondido pelo braço esse falatório raivoso que se repete há séculos e que só tem como resultado mostrar o poder que ela tem sobre o homem e o abuso certo que pode fazer disso. O senhor retira a luva com um gesto nervoso. Sua raiva passa inteiramente nesse gesto. A ideia era boa mas a atitude muito convencional da mulher estraga tudo: além do mais, a luz

* Professor do PPG em Ciências da Linguagem da UNISUL. 
que flui da lâmpada para os tecidos e as figuras é inexata. (Le Salon de 1883, in L'Art Moderne, 1883)

Se compararmos com a descrição que faz Gonzaga Duque do quadro de Belmiro veremos os vários pontos em comum:

É um episódio doméstico, uma rusga entre cônjuges. O marido, um rapaz de fortuna, chega em companhia da esposa à bonita habitação em que viviam até aqueles dias como dois anjos. Tudo em redor demonstra que aquele interior é presidido por um fino espírito feminino, educado e honesto. Ela, o encanto desse interior à bric-à-brac, depõe o toucado de palha sobre um mocho coberto por um belo pano de seda e entra em explicações com o esposo. E ele, muito a seu cômodo em um fauteuil de estofo sulferino, soprando o fumo de seu colorado havana, responde-Ihe palavra por palavra às explicações pedidas. Há um momento em que ela excede-se, diz uma frase leviana; ele reprova, ela retruca, ele repele; então ela não se pode conter, é subjugada por um acesso de ira, atira-se ao chão, debruça-se ao divã para abafar entre os braços o ímpeto do soluço. É este o momento que o artista escolheu. (DUQUE, 1995, p. 211)

Vale lembrar que Eulálio não fala em cópia e sim em glosa, palavra usada pelos poetas para dar conta de uma composição que desenvolve um mote, geralmente mantendo o número de versos do poema fonte e terminando cada estrofe com um verso do mote. A palavra indica ainda anotação entre as linhas ou na margem de um texto para explicar o sentido de uma expressão ou esclarecer uma passagem obscura; nota explicativa, comentário, ganhando, em seguida, também um caráter negativo (parecer contrário, censura, desaprovação). Etimologicamente, vem de glossa, língua, ponta, extremidade. A glosa de Belmiro, portanto, seria também um comentário ao quadro de Gervex que também tem outra versão do próprio Gervex. Belmiro inverteu a posição do casal em Arrufos [FIGURA 1]: o homem está à direita e a mulher, sentada no chão, sobre um belo tapete, de vestido rosa claro, chora apoiada em um pequeno sofá, cortando o quadro na diagonal. Está coberta pelo vestido e o único pedaço de corpo que se vê é a lateral do rosto. No quadro de Gervex [FIGURA 2], o homem ocupa o centro da tela, mas está em segundo plano, pois a mulher, de vestido branco, cruza nosso campo visual desde o primeiro plano do centro, com a cauda do vestido, até as longas luvas brancas que contrastam com os cabelos pretos, à direita. Em ambas, não se pode ver o rosto, estão chorando, fazendo cena, a de Belmiro, no chão, a de Gervex, em um pufe branco, apoiada sobre uma almofada azul. A versão de Belmiro parece mais sóbria, mais elegante, talvez, porque mais contida na quase uniformidade dos tons de marrom, vermelhos escuros e violetas, o que nos faz ficar mais concentrados na cena do arrufo; em Gervex, o branco do vestido, da cortina e do sofá, encobre a tela de uma luz mais carregada em contraste com o vermelho do tapete e das cortinas. O buquê de flores que chama nosso olhar no primeiro plano, à direita, bem ao lado da cauda do vestido da mulher se transforma, no quadro de Belmiro, em uma única flor, um 


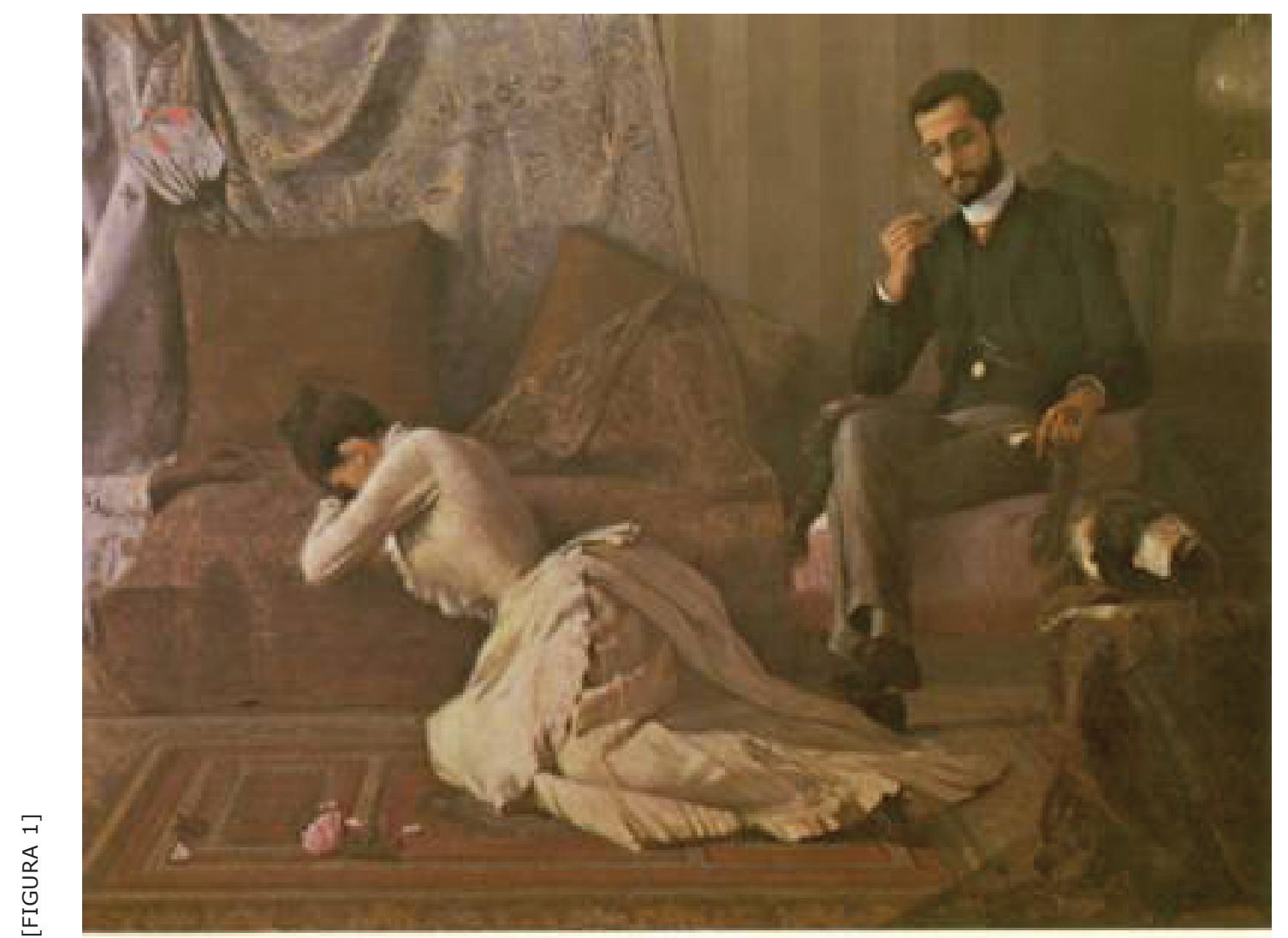

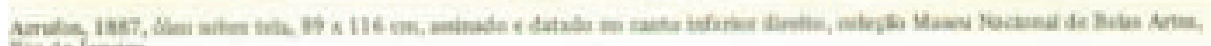
ine Se faming

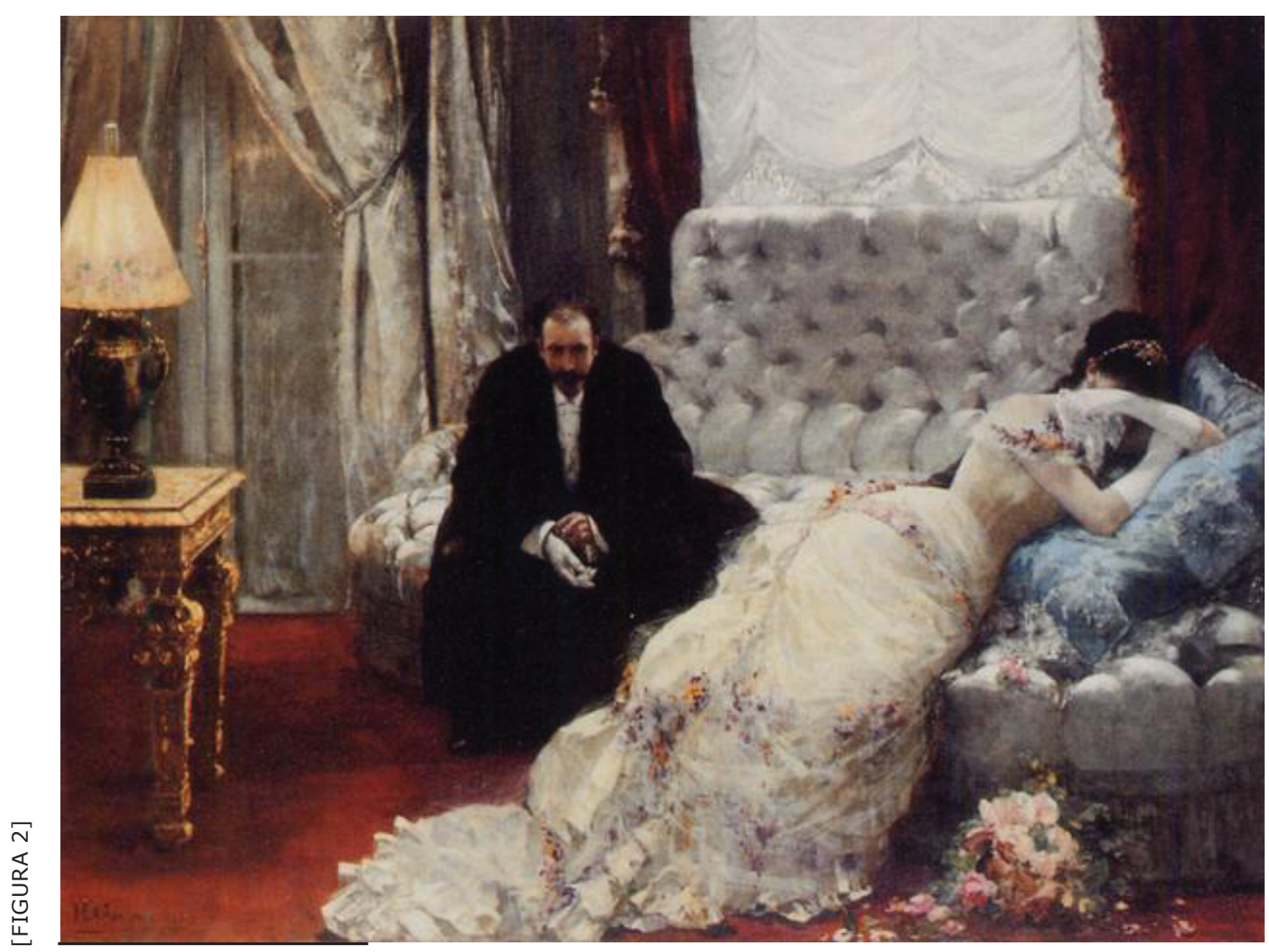


objeto mais expressivo, um signo do arrufo: caída sobre o tapete, com algumas pétalas desprendidas, jaz ao lado da mulher, à esquerda, como a mimetizar sua situação no detalhe. O homem de Le retour du bal demonstra uma raiva mais acentuada no gesto de tirar as luvas como bem percebe Huysmans e Zola, enquanto o de Belmiro simula superioridade olhando casualmente para seu charuto na mão direita, já sem a luva, como que distraído, alheio aos arrufos da companheira. Ele também faz cena, ele também joga. Temos ainda a diferença estampada nos títulos: enquanto o de Gervex apenas indica o momento do desentendimento, Le retour du bal, na volta do baile, o de Belmiro, Arrufos, traz todas as ressonâncias desse "agastamento ou mágoa de pouca duração entre pessoas que se estimam", como diz o dicionário, amuo, irritação, pois vem de rufo, amarelo-avermelhado, ruivo, cor de sangue, vermelho. A comparação entre as telas deixa clara a diferença de tratamento nas cores, na montagem da cena, na posição dos personagens e em sua atitude, enfatizando a diferença de estratégias e os efeitos produzidos pelos quadros. Gervex, que havia entrado no ateliê de Cabanel aos 19 anos, fez uma carreira de sucesso no final do século, não sendo nem um artista acadêmico tradicional, que vive das encomendas do Estado, dos prêmios de viagem etc., nem um independente que produz várias obras para depois vendê-las em exposições por intermédio de um marchand. Belmiro, por seu lado, divide a carreira de pintor com sua atividade nas revistas e jornais, onde atuava como caricaturista.

A questão da cópia e da sujeição ao mercado, apontada por Alexandre Eulálio, que nos remeteriam novamente às relações desiguais entre metrópole e periferia, por um lado, e por outro, a uma arte que se rebaixa para agradar seus clientes, poderiam ser vistam, no entanto, como estratégia de sobrevivência, de canibalismo, já que Belmiro, como pintor moderno, usa as armas que têm à mão para se manter em um campo ainda em formação e transita entre a academia e a indústria cultural. Arrufos é percebido por Gonzaga Duque como um quadro moderno exatamente por captar "o desideratum das sociedades modernas" na medida em que abandona os grandes temas históricos de Vitor Meireles e Pedro Américo para se deter em uma cena banal de briga entre amantes. Segundo ele, Belmiro é o primeiro a romper com os temas históricos, o primeiro a compreender claramente a arte de seu tempo, trazendo à baila um assunto novo: "Vai nisto uma questão séria - menos a de uma predileção do que a de uma verdadeira transformação estética" (DUQUE, 1995). O crítico leitor de Baudelaire percebe nitidamente aquilo que Jacques Rancière define como a passagem do regime representativo ou poético para o regime estético, ou seja, o momento em que as regras estabelecidas pelas poéticas, baseadas no par mímesis / poiésis, dá lugar a outra lógica que, no realismo literário fica clara com o rompimento, por exemplo, do privilégio das ações sobre os caracteres, ou da narração sobre a descrição. Ao recusar a noção de modernidade por ser ela "o conceito que se empenha em ocultar a especificidade desse regime das artes" (RANCIÈRE, 2005, p. 34), referindo-se ao regime estético, Rancière afirma que a ruptura entre o "antigo" e o "moderno" não está na passagem da figuração à não-figuração, ou do 
representativo ao anti-representativo, mas sim no realismo que, segundo ele, "não significa de modo algum a valorização da semelhança, mas a destruição dos limites dentro dos quais ela funcionava". (Idem, p. 35). A idéia é mostrar como a discussão sobre as artes no mundo contemporâneo está viciada por um parti pris, já que a noção de modernidade estética "recobre, sem Ihe atribuir um conceito, a singularidade de um regime particular das artes, isto é, um tipo específico de ligação entre modos de produção das obras ou das práticas, formas de visibilidade dessas práticas e modos de conceituação destas ou daquelas". (Ibid., p. 27). É para contestar essa noção, assim como a de vanguarda, que o teórico francês propõe três grandes regimes de identificação para as artes: o regime ético das imagens, momento em que a arte se encontra subsumida na questão geral das imagens, e a referência é Platão; o regime poético ou representativo, cuja referência é Aristóteles, e que está delimitado pelo par mímesis/ poiésis, sendo a mímesis não um princípio normativo que regula um domínio de semelhança entre cópias e modelos e sim "um princípio pragmático que isola, no domínio geral das artes (das maneiras de fazer), certas artes particulares que executam coisas específicas, a saber, imitações"; e, finalmente, um regime estético, ou seja, aquele em que a arte se torna singular, desobrigada de qualquer regra específica, da hierarquia de temas, gêneros e artes. Para encurtar a exposição, Rancière afirma então que aquilo que se costuma chamar de pósmodernismo é apenas a consciência do fim de um determinado paradigma, qual seja, "a tentativa desesperada de fundar um 'próprio da arte' atando-o a uma teleologia simples da evolução e da ruptura históricas". (Ibid., p. 41). O próximo passo de Rancière é mostrar que se o regime estético se define exatamente como a "ruína do sistema da representação", ou seja, dos valores e normas que regiam as artes desde Aristóteles até o início do século XIX, é nele que a literatura torna possível, por exemplo, a fotografia, contestando assim as teses dos teóricos que viam na singularidade da máquina (fotográfica ou cinematográfica) a mágica dessas novas artes técnicas. O realismo literário prefigura a fotografia na medida em que rompe com a hierarquia dos temas e dos gêneros e passa a focalizar o homem comum, permitindo assim que o detalhe possa revelar 0 todo.

O que parecia claro ao crítico Gonzaga Duque naquele momento, a novidade e a modernidade do gesto de Belmiro, passou em branco pela geração modernista que acreditava realizar uma ruptura com o passado na medida em que, por exemplo, rompia com o realismo considerado então como regressivo em relação à grande causa da modernidade que seria a "desintegração do signo" para colocar em causa "a estética secular da 'representação'", como afirmava em "O efeito de real", Roland Barthes (1988: 165). Por isso, Mário de Andrade, ao falar sobre a vinda de Lasar Segall ao Brasil em 1912, afirmava que o país não poderia perceber a presença do pintor lituano, pois vivia então em plena "unanimidade acadêmica". (ANDRADE, 1984, p. 47)

Para um pensador como Georg Simmel, a tendência realista ou naturalista, que "não provém de um interesse pela natureza e sim pela arte", consiste em uma 
aproximação aos objetos - a focalização fragmentada ou próxima de Rancière -, enquanto no simbolismo o que está em jogo é o "encanto da distância" (der Reiz der Distanz). No ensaio Vom Realismus in der Kunst ( $O$ realismo na arte), que sai na revista berlinense "Der Morgen", em 1908, Simmel tem o cuidado de separar um alto (höhe) realismo que nunca está preocupado exclusivamente com a mera visibilidade (die blosse Anschaulichkeit), assim como um naturalismo não-artístico (der unkünstlerische Naturalismus) de outro mais refinado (feinere) ou de grande estilo (der Naturalismus grossen Stiles): seu objetivo é, depois de demonstrar a impossibilidade de limitar o realismo à imitação externa dos conteúdos da realidade, jogar contra ele a censura que faz à arte idealista, pois na medida em que está centrado no "ser das coisas" e a arte só trabalha com as "formas de ser" e não com o "ser das formas", o realismo também tem seu centro fundamental fora da arte, assim como acontece no idealismo que se centra na idéia, no ideal, algo para além da arte e que faz dela apenas um meio. "Se o realismo quer se defender dessa legislação estrangeira que faz da arte apenas um meio, não deve esquecer que ao deixar a realidade como realidade atuar na obra $(. .$.$) comete exatamente o mesmo erro. Ele serve à idéia 'reali-$ dade' da mesma maneira que outros, à idéia religião ou moral ou pátria". Nesse momento, Simmel já havia se afastado dos naturalistas, de Gerhart Hauptmann, do encanto da proximidade, e se aproximado dos simbolistas, de Stefan George, do encanto da distância. Em um texto decisivo para essa mudança, Soziologische Ästhetik, de 1896, diz o mestre de Benjamin e Lukács: "O naturalismo em suas formas rudes foi uma tentativa desesperada de não se conformar com a distância, de se agarrar à proximidade das coisas e à imediaticidade, mas, tão logo estavam próximos delas, as pessoas de nervos sensíveis não puderam mais suportar seu contato e se espantaram como se estivessem segurando carvão em brasa."

A estratégia de Belmiro de Almeida, então, seria uma aproximação ao mundo burguês através da construção de uma cena da intimidade de um casal, uma cena banal, corriqueira, típica desse momento moderno, mas também através da apropriação de um tema trabalhado anteriormente pelo pintor francês Henri Gervex. Assim, o pintor de Arrufos parece, por um lado, não estar nem um pouco distante das estratégias dos modernistas paulistas do início do século XX. Como eles, tem um olho aqui, outro lá; como eles, está em dia com as tendências européias que se libertam dos modelos da academia; como eles, saqueia o arquivo do centro para devolver uma obra que, como afirma Silviano Santiago, atua como um enriquecimento suplementar. Esgotado o modelo modernista é preciso pensar a arte do século XIX sob outros parâmetros, é preciso abrir o véu da "unanimidade acadêmica" para, por trás dele, descortinar as telas de Almeida Júnior, de Rodolfo Amoedo, as paisagens de Georg Grimm, entre outros. É preciso, ainda, pensar o realismo fora dos estreitos liames da mímesis, como construção textual ou pictórica, como o encanto da proximidade. 


\section{Referencias bibliográficas:}

ANDRADE, Mário. Lasar Segall. In: Aspectos das Artes Plásticas no Brasil. $3^{a}$ ed. Belo Horizonte: Itatiaia, 1984.

BARTHES, Roland. O efeito de real. In: O rumor da língua. Tradução Mário Laranjeira, prefácio Leyla Perrone-Moisés. São Paulo: Brasiliense, 1988.

DUQUE, Gonzaga. A arte brasileira. Introdução e notas Tadeu Chiarelli. Campinas: Mercado de Letras, 1995.

EULÁLIO, Alexandre. O século XIX - Tradição e Ruptura (Panorama das artes plásticas). In: Escritos. Berta Waldman e Luiz Dantas, org. São Paulo: Unesp, 1992.

MONNIER, Gerard. Un Itinéraire Atypique au XIXe Siècle: La carrière du peintre Henri Gervex (1852-1929). In: Revista de História da Arte e Arqueologia, número 4, agosto de 2000.

RANCIÈRE, Jacques. A partilha do sensível. Estética e política. Tradução Mônica Costa Neto. São Paulo: EXO experimental org. e Ed. 34, 2005.

SIMMEL, Georg. Soziologiosche Ästhetik. In: Georg Simmel Gesamtausgabe. Frankfurt: Suhrkamp, vol 5, 1992.

. Vom Realismus in der Kunst. In: Gesammtausgabe. Band 8, Ausätze und Abhandlungen 1901-1908 Band II, Herausgegeben von Alessandro Cavalli und Volkhard Krech. Frankfurt am Main: Suhrkamp, 1997.

. Zum Problem des Naturalismus. In: Gesammtausgabe, Band 20: Postume Veröffentlichungen, Ungedrucktes, Schulpädagogik, Herausgegeben von Torge Karlsruhen und Otthein Rammstedt. Frankfurt am Main: Suhrkamp, 2006.

ZOLA, Emile. A batalha do impressionismo. Tradução Martha Gambini. Rio de Janeiro: Paz e Terra, 1989.

\section{Title:}

Belmiro de Almeida and realism. From the gloss to the enchantment of proximity

\section{Abstract:}

In this essay one reflects, through a version by Belmiro de Almeida of a painting by Henri Gervex, on the issue of Realism not as mimesis, but as the moment of rupture with the representative regime (Rancière), and of the "copy" as gloss, that is, as a cannibal version of an European "original."

\section{Keywords:}

Mimesis; realism; XIXth century 